\title{
A Virtuous Company Makes Me Engage! The Mediation Role of Organizational Identification in the Workplace
}

\author{
Inggil Sholata Sya ${ }^{\mathrm{a}}$ and Arum Etikariena Hidayat ${ }^{\mathrm{b}}$
}

${ }^{a}$ Faculty of Psychology, Universitas Indonesia, Depok, Indonesia; ${ }^{b}$ Department of Industrial and Organizational Psychology, Faculty of Psychology, Universitas Indonesia, Depok, Indonesia

*Corresponding author:

Arum Etikariena Hidayat

Department of Industrial and Organizational Psychology

Faculty of Psychology, Universitas Indonesia

Depok, Jawa Barat, Indonesia

Email address: arum.etikariena@ui.ac.id / arum.hidayat@gmail.com 


\title{
A Virtuous Company Makes Me Engage! The Mediation Role of Organizational Identification in the Workplace
}

\begin{abstract}
This study shows the effect of perceived organizational virtuousness on work engagement. Based on social identity theory, the researchers hypothesize that organizational identification mediates the relationship between perceived organizational virtuousness and work engagement. This study analyzes data from online and offline questionnaires given to 84 participants from various work sectors. The measurements of the study are the Short Utrech Work Engagement Scale (UWES-9), Organizational Identification Scale, and Organizational Virtuousness Perceived Scale. The data were analyzed with regression analysis using SPSS 25.0. The results show that perceived organizational virtuousness significantly affected work engagement, perceived of organizational virtuousness was significantly related to organizational identification, organizational identification was significantly related to work engagement, and the relationship between perceived organizational virtuousness and work engagement was fully mediated by organizational identification. These findings support the social identity theory that organizational identity mediates the relationship between perceived organizational virtuousness and work engagement. This study provides a needed step forward to building a virtuous climate in an organization.
\end{abstract}

Keywords: organizational identification, perceived organizational virtuousness, work engagement, regression analysis

\section{Introduction}

In recent decades, the majority of psychology researchers have focused on negative phenomena such as stress, anxiety, and depression (Seligman, 2002). Ugwu (2012) changed the perspective of research from the negative aspects of behavior to positive aspects in the field of psychology, investigating the development and growth of individuals, organizations, and society. Research revealed a positive approach that increases work productivity and controls negative work factors. This approach, called Positive Organizational Behavior (POB), emphasizes the development of human resources in the workplace. Human resources are considered the most valuable assets of an organization, where they play an important role (Bouckenooghe, Raja, \& Abbas, 2014One aspect that is relevant to POB is work engagement.

Schaufeli et al. (Bernt, 2016) explained that "work engagement is understood to be a motivational construct defined as a positive, fulfilling, work-related state of mind that is characterized by vigor, dedication, and absorption." Schaufeli et al. stated that, "Vigor was regarded as a physical component, which entails high levels of energy and mental resilience while working, the willingness to invest effort in one's work, and persistence even in the face of difficulties" (Bernt, 2016). Schaufeli et al. explained, "dedication is an emotional component characterized by a sense of significance, enthusiasm, inspiration, pride, and challenge at work" (Bernt, 2016). According to Bakker, Hakanen, Demerouti, and Xanthopoulou, "Absorption is 
considered a cognitive component, which consists of being fully concentrated, happy, and deeply engrossed in one's work, experiencing that time passes quickly, and difficulty detaching oneself from work" (Bernt, 2016).

Work engagement is neither a momentary nor a specific condition because it is more permanent and can penetrate the level of cognition. It motivates employees to feel commitment, enthusiasm, and passion because they have energy and a positive relationship with their work. In addition, they have a strong self-identification with their work and see their workplace as meaningful.

Employees are engaged in their work and motivated to foster strong emotional bonds when their perception of the organization in which they work is that it has a culture that cares for employee well-being, demonstrates prosocial behavior (Rhee, Dutton, \& Bagozzi, 2006), and can improve work effort. Cameron, Bright, and Caza (2004) stated that organizational virtue can be defined as the actions, desires, and processes of individuals or groups that spread goodness in an organization to create positive emotions in employees and motivate them to help and respect one another (Bagozzi, 2003). The organizational context that fosters working relationships can be trusted. In addition, Bakker et al. (2011) found a significant relationship between an organization's failure to realize its values and lack of integrity, and a decreased level of employee work engagement.

Tyler (2012) argued that "when organizational membership contributes to a positive social identity, employees will be psychologically involved with the organization and work." In addition, Dutton, Dukerich, \& Harquail (1994) stated that an organization's positive qualities such as virtues and value characteristics are related to organizational identification (KaranikaMurray, Duncan, Pontes, \& Griffiths, 2015). Ashforth and Mael described "the perception of oneness with or belongingness to an organization, where the individual defines him or herself in terms of the organization in which he or she is a member" (Hur, Shin, Rhee, \& Kim, 2017). A sense of unity and belonging in organization can be built by employees who identify with the organization, called organizational identification. Organization members can build a stronger positive self-image by identifying with organizations that have interesting, valuable attributes and seeing similarities between themselves and the organizational attributes. Grant argued that "when employees see their organization showing optimism, forgiveness, trust, compassion, and integrity, employees tend to generalize their perceptions as decisive organizational property" (Hur et al., 2017).

Hur et al. (2017) asserted that perceived organizational virtues and involvement are derived from organizational membership and can promote effective work and facilitate motivated behavior. According to Martin and Cullen (2006) "This is consistent with the context-attitudebehavior framework which shows that employees who are embedded in the organizational context influence their attitudes and behavior." Cameron (2003) stated that organizations characterized as virtuous contribute to behavioral friendliness and employee motivation. Tajfel (Hur, Rhee, \& Ahn, 2016) described organizational identification as a connecting mechanism between the perception of organizational creativity and work engagement. As mentioned in 
Singh, David, and Mikkilineni (2018), Bagozzi suggested that positive organizational features (e.g., organizational virtues and strengths) improve organizational identification, lead to absorption, and promote vigor and dedication. There are four hypotheses proposed in this research.

$\mathrm{H}_{1}$ : Perceived organizational virtuousness is positively related to work engagement.

$\mathrm{H}_{2}$ : Organizational identification is significantly related to perceived organizational virtuousness.

$\mathrm{H}_{3}$ : Organizational identification is significantly related to work engagement.

$\mathrm{H}_{4}$ : Organizational identification fully mediates perceived organizational virtuousness and work engagement.

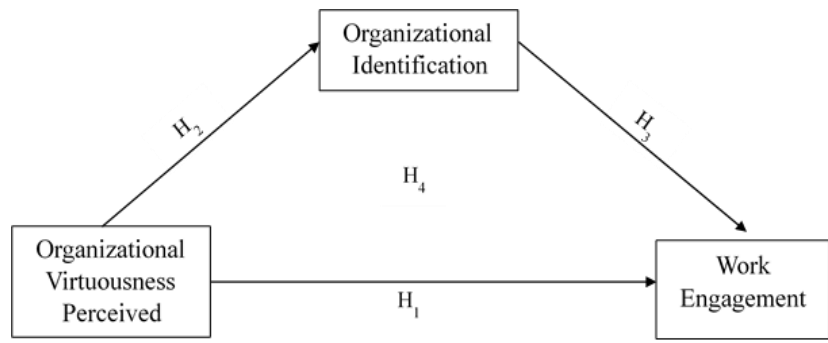

Fig. 1. Research model

\section{Methods}

\section{Participant and Procedures}

A convenience sampling method was used to select the participants because it is convenient, simple, not time consuming, and economical (Huysamen, 1994). The participants were 84 employees (57\% female) in Indonesia from four sectors (BUMN, civil service, public employees, and ministries) who had worked for a minimum of two years at their organization. Their typical education level was undergraduate degree (76\%). Table I shows the means (M), standard deviation (SD), Pearson correlation (r), and Cronbach's $\alpha$ for all variables. In this research, Cronbach's $\alpha$ implies a high measure of internal consistency of the variables. Furthermore, it has a moderate and significant correlation among the constructs. Baron and Kenny (1986) stated that if there is a significant correlation among constructs, the researcher can propose mediation analysis.

Table I. Mean, Standard Deviation, Correlation, and Cronbach's $\alpha$

\begin{tabular}{|c|c|c|c|c|c|c|c|c|c|}
\hline & $\mathbf{M}$ & SD & 1 & 2 & 3 & 4 & 5 & 6 & 7 \\
\hline 1. Sex & 1.57 & 0.50 & - & & & & & & \\
\hline 2. Age & 30.79 & 6.72 & 0.05 & - & & & & & \\
\hline 3. Education & 2.76 & 0.63 & 0.06 & $.23^{*}$ & - & & & & \\
\hline 4. Work Sector & 2.11 & 0.94 & $-.29^{* *}$ & 0.04 & 0.16 & - & & & \\
\hline 5. Work Engagement (WE) & 43.63 & 9.41 & 0.08 & 0.16 & -0.01 & 0.02 & (.93) & & \\
\hline 6. Organizational Virtuousness (OVP) & 46.86 & 5.73 & -0.07 & 0.01 & -0.02 & $.22^{*}$ & $.47^{* *}$ & $(.90)$ & \\
\hline 7. Organizational Identification (OI) & 15.5 & 2.16 & -0.08 & 0.05 & 0.02 & 0.17 & $.54^{* *}$ & $.75^{* *}$ & $(.72)$ \\
\hline
\end{tabular}




\section{Measurements}

The perception of organizational virtuousness was assessed with 15 items adapted from the scales of Hur et. al (2017). There are five sub-dimensions of the questionnaire: compassion, optimism, trust, integrity, and forgiveness. The scales were adapted to Bahasa Indonesia. The participants were asked to rate their perception of their organization's culture on four-point Likert scale (from $1=$ strongly disagree to $4=$ strongly agree). The Cronbach's $\alpha$ was. 90 .

Organizational identification was determined by the Organizational Identification Scale adapted from Ashforth and Mael (1989). The scale was adapted to Bahasa Indonesia. It assessed how much the participants defined themselves in the terms of their organization. The questionnaire consisted of five items in which the participants indicated their level of agreement on a fourpoint Likert scale (from $1=$ strongly disagree to $4=$ strongly agree). The Cronbach's $\alpha$ was about.72.

Work engagement was measured by the short version of the Utrech Work Engagement Scale, with nine items (UWES-9; Schaufeli, Bakker, \& Salanova, 2006). The questionnaire consisted of three subscales: vigor, dedication, and absorption. The scales were adapted to Bahasa Indonesia. The participants were asked to indicate their feelings about work on a seven-point Likert scale (from $0=$ never to $6=$ always). The Cronbach's $\alpha$ was.93.

\section{Data Analysis}

The data were analyzed by regression analysis using SPSS 25.0. Following Baron and Kenny (1986), when a predictor variable and an outcome have a relationship, mediation analysis can be performed to determine the need for mediation analysis. A series of standard multiple regression analyses were completed to examine whether organizational identification mediated perceived organizational virtuousness and work engagement.

\section{Results}

Simple linear regression was used to analyze the mediation effect between variables for unmediated pathways. Table II shows the results of testing hypotheses 1 to 3 . The first model indicated that perceived organizational virtuousness was a significant predictor of work engagement, $\mathrm{F}(1,82)=23.28, \mathrm{p}<.005, \mathrm{R}^{2}=.22$. Perceived organizational virtuousness explained $22 \%$ of the variance in work engagement. The second model indicated that organizational identification was significantly predicted by perceived organizational virtuousness, $\mathrm{F}(1,82)=108.09, \mathrm{p}<.05$. Further, $57 \%$ of the variance in organizational identification was explained by perceived organizational virtuousness $\left(\mathrm{R}^{2}=.57\right)$. Additionally, organizational identification positively predicted work engagement, $\mathrm{F}(1,82)=33.53$, $\mathrm{p}<.05$, $\mathrm{R}^{2}=.29$. Twenty-nine percent of the variance in organizational identification was explained by work engagement. 
Table II. Analysis of Simple Linear Regression for How Perceived Organizational Virtuousness Affects Organizational Identification and Work Engagement

\begin{tabular}{|c|c|c|c|c|}
\hline & Variables & $\overline{\mathbf{R}^{2}}$ & $\mathbf{F}$ & $\boldsymbol{\beta}$ \\
\hline \multirow{3}{*}{ Without Mediation } & $\begin{array}{l}\text { Perceived Organizational Virtuousness - } \\
\text { Work Engagement }\end{array}$ & .22 & 23.28 & .47 \\
\hline & $\begin{array}{l}\text { Perceived Organizational Virtuousness - } \\
\text { Organizational Identification }\end{array}$ & .57 & 108.09 & .75 \\
\hline & $\begin{array}{l}\text { Organizational Identification - Work } \\
\text { Engagement }\end{array}$ & .29 & 33.53 & .54 \\
\hline
\end{tabular}

Note. $\mathrm{R}^{2}$ : adjusted R-square; degrees of freedom $(\mathrm{df})=83 ; \mathrm{R}^{2}$ : regression coefficient. $\mathrm{p}<.05$

Table III shows the results of the mediation analysis using multiple regression. Organizational identification fully mediated perceived organizational virtuousness and work engagement, $\mathrm{F}$ (2, $81)=17.33, \mathrm{p}<.05, \mathrm{R}^{2}=.30$. In addition, organizational identification mediated $30 \%$ of the total effect.

Table III. Results of Multiple Regression for How Perceived Organizational Identification Mediates Organizational Virtuousness and Work Engagement

\begin{tabular}{|c|c|c|c|c|c|}
\hline & Variables & & $\mathbf{R}^{2}$ & $\mathbf{F}$ & $\boldsymbol{\beta}$ \\
\hline $\begin{array}{l}\text { With Mediation of } \\
\text { Organizational } \\
\text { Identification }\end{array}$ & $\begin{array}{l}\text { Perceived Organizational } \\
\text { Work Engagement }\end{array}$ & Virtuousness & .30 & 17.33 & .55 \\
\hline
\end{tabular}

Note. $\mathrm{R}^{2}$ : adjusted R-square; degrees of freedom $(\mathrm{df})=83 ; \mathrm{R}^{2}$ : regression coefficient. $\mathrm{p}<.05$

\section{Discussion}

The mediation mechanism of organizational identification underlaid how perceived organizational virtuousness related to work engagement. As expected, perceived organizational virtuousness significantly affected work engagement, and employees become engaged in their work based on their perception of how the organizational culture cared for employee well-being and demonstrated prosocial behavior (Cameron et al. 2004). Ugwu (2012) explained that an organization with a strong culture of values (e.g., forgiving employees' mistakes) inspires employees to self-identify with these virtues and to act out the virtues with others. This builds their interest and affection for the organization and ultimately leads to stronger work engagement.

Organizational identification has a significant relationship with work engagement. When employees self-identify with the values of their organization, their attitudes and beliefs are positive and they are motivated to improve their work performance. Social identity theory shows that strong ties between employees and their organizations strengthen their motivation to exert effort for (and on behalf of) both their peers and their organizations (Ashforth \& Mael, 1989; Dutton et al., 1994). In turn, a strong psychological bond with the organization can strengthen their willingness to work better and be bound by the work itself.

Perceived organizational virtuousness had a positive relationship with organizational identification. Organizations that have a unique culture affect employees' self-identification, 
especially when the employee believes the organization's values are the same as his or her own. Ashforth and Mael described "the perception of oneness with or belongingness to an organization, where the individual defines him or herself in terms of the organization in which he or she is a member" (Karanika-Murray et al., 2015).

The relationship between perceived organizational virtuousness and work engagement was fully mediated by organizational identification. Within organizations, employees should foster high quality connections with each other. These can be built based on the understanding that a positive picture of the organization produces positive emotions (Dutton \& Heaphy, 2003). Positive interaction with other employees in the organization allows employees to create a positive spiral of meaning in the workplace (Csikszentmihalyi, 2003) and foster job involvement. Based on social identity theory (Tajfel in Hur 2017), organizational identification is the connecting mechanism between perceived organizational creativity and work engagement. Bagozzi (Singh et al., 2018) stated that positive organizational features (e.g., organizational virtues and strengths) enhance organizational identification, lead to absorption, and promote vigor and dedication.

\section{Conclusion}

The study found that perceived organizational virtuousness significantly affected work engagement and organizational identification, organizational identification significantly predicted work engagement, and fully mediated perceived organizational virtuousness and work engagement. A positive culture can be established through organizational identification, and this may be used to build employee engagement.

\section{Theoretical Implications}

The findings of this research have implications for education. One one hand, the research on organizational virtuousness is the first study of its kind in Indonesia. The results show that perceived organizational virtuousness affects employee work engagement. At the same time, the findings support the social identity theory that organizational identification is a relevant framework for explaining how perceived organizational virtuousness is associated with work engagement.

\section{Practical Implications}

Other findings have implications for management. Rego, Ribeiro, \& Cunha. (2010) stated that employees' divarication can be increased by raising their perception of the organization's values. Managers should be aware of and care about employees' perception of the organizational climate. They should seek to build a virtuous climate within the organization. Employees' perception of the organizational climate should be known and evaluated by management because it is fundamental to employees' well-being. Therefore, management must focus on developing an atmosphere that encourages virtuousness in the organization. 


\section{Future Research}

Future research should investigate the relation of the five dimensions of organizational virtuousness and three dimensions of work engagement, identify boundary conditions where certain types of work become more prominent than others, and explore cross-linking from various organizations.

\section{References}

Ashforth, B. E., \& Mael, F. (1989). Social identity theory and the organization. Academy of management review, 14(1), 20-39.

Bakker, A. B., Albrecht, S. L., \& Leiter, M. P. (2011). Key questions regarding work engagement. European journal of work and organizational psychology, 20(1), 4-28.

Baron, R. M., \& Kenny, D. A. (1986). The moderator-mediator variable distinction in social psychological research: Conceptual, strategic, and statistical considerations. Journal of personality and social psychology, 51(6), 1173.

Bernt, P. E. H. (2016). Work engagement as a mediator in the relationship between HRM-practices and employee performance (Master thesis). University of Oslo, Oslo.

Bouckenooghe, D., Raja, U., \& Abbas, M. (2014). How does self-regulation of emotions impact employee work engagement: The mediating role of social resources. Journal of Management and Organization, 20(4), 508-525. https://doi.org/10.1017/jmo.2014.43

Cameron, K. S. (2003). Organizational virtuousness and performance. Positive organizational scholarship, 48 , 65.

Cameron, K. S., Bright, D., \& Caza, A. (2004). Exploring the Relationships between Organizational Virtuousness and Performance. American Behavioral Scientist, 47(6), 766-790.

Csikszentmihalyi, M. (2004). Good business: Leadership, flow, and the making of meaning. New York: Penguin.

Dutton, J. E., Dukerich, J. M., \& Harquail, C. V. (1994). Organizational images and member identification. Administrative science quarterly, 239-263.

Dutton, J. E., \& Heaphy, E. D. (2003). The power of high-quality connections. Positive organizational scholarship: Foundations of a new discipline, 3, 263-278.

Guchait, P., Lanza-Abbott, J. A., Madera, J. M., \& Dawson, M. (2016). Should organizations be forgiving or unforgiving? A two-study replication of how forgiveness climate in hospitality organizations drives employee attitudes and behaviors. Cornell Hospitality Quarterly, 57(4), 379-395.

Hur, W. M., Rhee, S. Y., \& Ahn, K. H. (2016). Positive psychological capital and emotional labor in Korea: the job demands-resources approach. The International Journal of Human Resource Management, 27(5), 477500.

Hur, W. M., Shin, Y., Rhee, S. Y., \& Kim, H. (2017). Organizational virtuousness perceptions and task crafting: The mediating roles of organizational identification and work engagement. Career Development International, 22(4), 436-459.

Huysamen, G. K. (1994). Methodology for The Social and Behavioural Science. Halfway House: Southern Book Publishers.

Karanika-Murray, M., Duncan, N., Pontes, H. M., \& Griffiths, M. D. (2015). Organizational identification, work engagement, and job satisfaction. Journal of Managerial Psychology, 30(8), 1019-1033. https://doi.org/10.1108/JMP-11-2013-0359

Martin, K. D., \& Cullen, J. B. (2006). Continuities and extensions of ethical climate theory: A meta-analytic review. Journal of business ethics, 69(2), 175-194.

Rego, A., Ribeiro, N., \& Cunha, M. P. (2010). Perceptions of organizational virtuousness and happiness as predictors of organizational citizenship behaviors. Journal of Business Ethics, 93(2), 215-235.

Rhee, S. Y., Dutton, J. E., \& Bagozzi, R. P. (2006). Making sense of organizational actions with virtue frames and its links to organizational attachment. Journal of Management, Spirituality \& Religion, 3(1-2), 34-59.

Schaufeli, W. B., Bakker, A. B., \& Salanova, M. (2006). The measurement of work engagement with a short questionnaire: A cross-national study. Educational and psychological measurement, 66(4), 701-716. 
Seligman, M. E. (2002). Positive psychology, positive prevention, and positive therapy. Handbook of positive psychology, 2(2002), 3-12.

Singh, S., David, R., \& Mikkilineni, S. (2018). Organizational Virtuousness and Work Engagement: Mediating Role of Happiness in India. Advances in Developing Human Resources, 20(1), 88-102. https://doi.org/10.1177/1523422317741885

Tyler, T. R. (1999). Why people cooperate with organizations: An identity-based perspective. In R. I. Sutton \& B. M. Staw (Eds.), Research in organizational behavior (Vol. 21, pp. 201-246). US: Elsevier Science/JAI Press.

Ugwu, F. O. (2012). Are good morals often reciprocated? Perceptions of organizational virtuousness and optimism as predictors of work engagement. Asian Journal of Social Sciences \& Humanities, 1(3), 188-198. 